Girl's College of Education, Riyadh, Saudi Arabia

\title{
MOULD MYCOFLORA OF SOME SAUDI ARABIAN POTATO CHIPSY
}

(With 2 Tables)

\author{
By \\ LAILA A. NASSER \\ (Received at 19/8/1999)
}

الفلورا الفطرية لبعض أنواع الثبيسي في المملكة العربية السعودية لبلِم أحدد ناصر

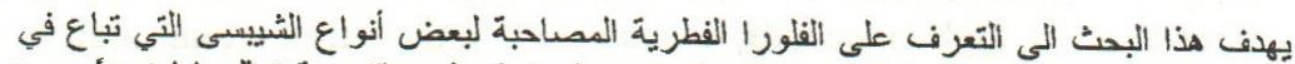

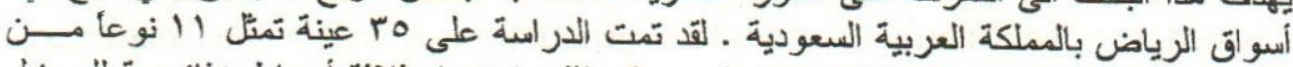

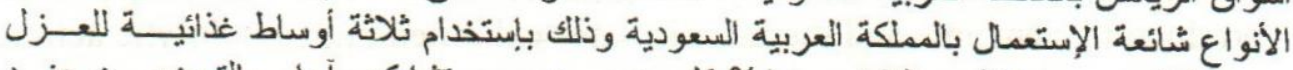

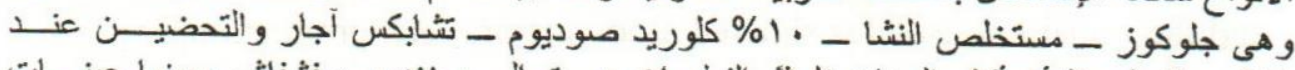

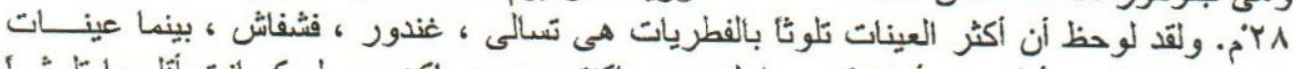

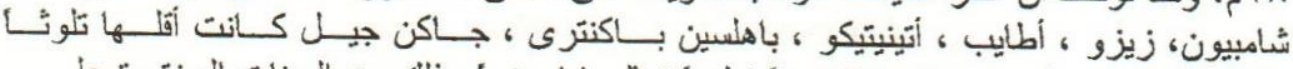

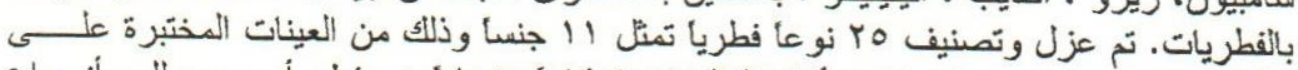

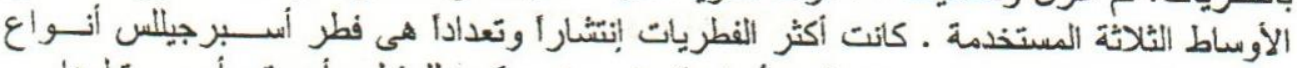

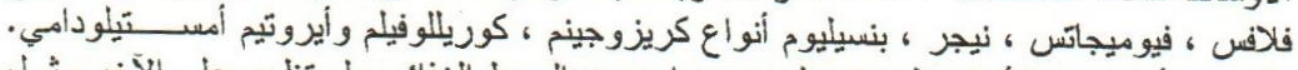

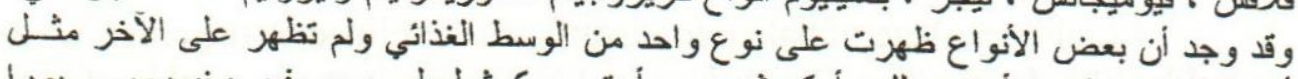

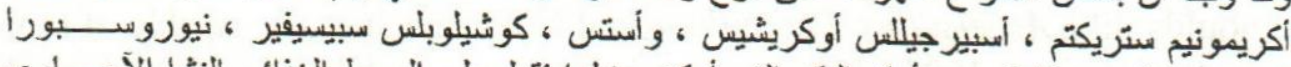

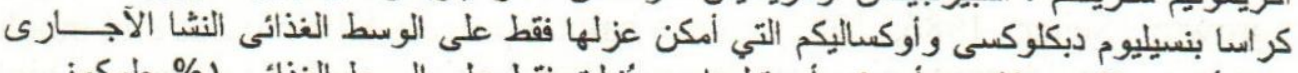

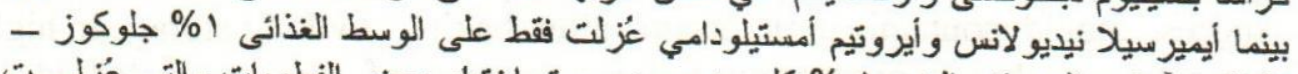

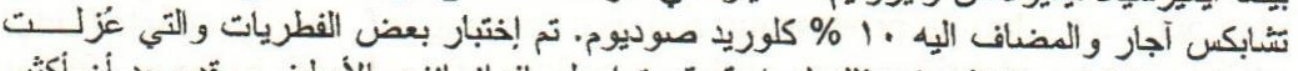

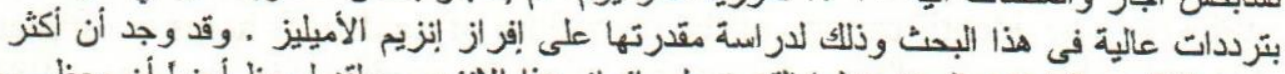

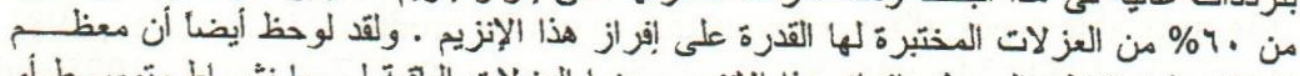

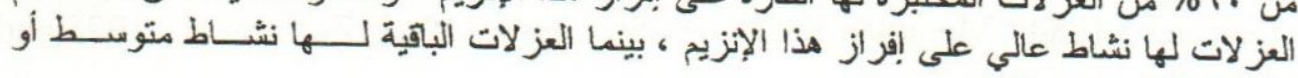

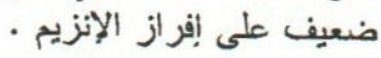




\section{SUMMARY}

Survey of mycoflora in 35 samples representing 11 kinds of chipsy commonly consumed in Saudi Arabia was evaluated using 1\% glucose-, $1 \%$ starch-, and $10 \%$ sodium chloride-Czapek's agar at $28^{\circ} \mathrm{C}$. The most contaminated samples were Tasali, Gandour, and Fesh fash with high incidence of mycoflora while samples of Champion, Zizo, Ataib, Authentico, bahlesen picantrie and Jack'n jill were less contaminated with fungi. Twenty-five species representing 11 genera were isolated from the samples tested on the three media used. The most frequently isolated fungi were Aspergillus flavus, A. fumigatus, A. niger, Penicillium chrysogenum, $P$. corylophilum and Eurotium amstelodami. The starch-decomposing species such as Acremonium strictum, A. ochraceus, A. ustus, Cochliobolus spicifer, Neurospora crassa, Penicillium dauclauxi and P. oxalicum were only isolated on starch agar plates whereas the halophilic or halotolerant Emericella nidulans and Eurodium chevalieri were only encountered when using $1 \%$ glucose-Czapek's agar medium supplemented with $10 \%$ sodium chloride. The high frequently encountered fungi in the current study were tested for their ability to amylase production. $60 \%$ of the isolates could produce this enzyme and the most isolates exhibited high amylolytic activity and the remaining isolates showed moderate or weak production.

Key words: Mould mycoflora, Potato

\section{INTRODUCTION}

Mould spoilage of baked foodstuffs was confined to the crust, where moulds like Aspergillus, Penicillium and Cladosporium are capable of rapid growth (Seiler, 1986, 1987). Since baking process kills moulds and mould spores, mould contamination occurs after baking by long storage in high temperature, during processing and transporting of food products (Odell, 1983). The identification of the mycoflora of foodstuffs helps to estimate the probable types of mycotoxins that might be produced (King et al., 1981; Leistner, 1984; Megalla et al., 1985; Lacey, 1988; Zohri et al., 1995 and Siame et al., 1998).

Chipsy is one of the most popular food products consumed in Saudi Arabia especially by children as well as in the other countries. They are prepared mainly from baked potatoes and other ingredients such as vegetable oils, natural flavours, salts and spices. Contamination of 
foodstuffs with spoilage fungi leading to great economic losses (Beuchat, 1978), besides constituting a major public health hazard by producing a wide variety of mycotoxins (FAO, 1979).

This study assessed the mould populations associated with different kinds of chipsy and the production of the enzyme amylase by the fungi that could lead to degradation of the ingredients was also evaluated.

\section{MATERIAL and METHODS}

Thirty-five samples of eleven different trade marks of chipsy were collected from shops/markets in Riyadh, Saudi Arabia. The samples were transferred to the laboratory and kept in a refrigerator $\left(5-7^{\circ} \mathrm{C}\right)$ until identification of the fungi had been undertaken.

Determination of fungi:

Three media were used for this propose: $1 \%$ glucose-, $1 \%$ starch and $10 \%$ sodium-chloride-Czapek's agar. Five segments of snack (chipsy) were put on the surface of each agar plate, nine plates for each sample ( 3 each medium) were used. The plates were incubated at $28^{\circ} \mathrm{C}$ for $1-2$ weeks, and the growing fungi were identified (Raper and Fennell, 1977; Pitt, 1979; Domsch et al., 1980; Kozakiewicz, 1989).

\section{Screening for amylase enzyme production:}

Starch hydrolysis was detected on Czapek's agar with the sucrose replaced by $10 \mathrm{~g}$ soluble starch. A positive reaction was indicated by the appearance of a clear zone around the colony after flooding with Gram's iodine solution (Bridge, 1985).

\section{RESULTS}

Results are obtained at Tables 1 and 2.

\section{DISCUSSION}

A total viable counts of fungi in the samples tested fluctuated from 140-219 colonies/525 segments in all samples, on glucose- (151 colonies), starch- (140 colonies) and $10 \% \mathrm{NaCl}$-Czapek's agar $(219$ colonies $)$ at $28^{\circ} \mathrm{C}$. Tasali, Gandour and Fesh Fash snacks had the highest number of fungi and Champion, Zizo, Ataib, Authentico, bahlesen Picontrie and Jack's Jill the lowest (Table 1). 
Twenty-five species representing 11 genera were isolated from the samples tested on glucose- (16 species +7 genera), starch- $(16+6)$ and $10 \%$ $\mathrm{NaCl}$-Czapek's agar $(13+4)$ at $28^{\circ} \mathrm{C}$. In this respect, most of these fungi have been reported previously from different food materials such as snacks (Zohri et al., 1995), Biscuits (Abdel-Sater and Ismail, 1993) some grains and seeds (El-Kady et al., 1982; Abdel-Hafez, 1984; Megalla et al., 1985; Lund et al., 1996; Viljoen and Holy, 1997) as well as from other foods (Samson et al., 1995; Scholte, 1995; Hartog and Kuik, 1984)

Aspergillus (10 species) was the most prevalent genus encountered in $86 \%, 91 \%$ and $69 \%$ of the samples comprised $68.2 \%, 75.7 \%$ and $52.9 \%$ of total fungi, on glucose-, starch- and 10\% NaCl-Czapek's agar, respectively. The most frequently encountered species from the genus were: A. flavus, A. fumigatus and A. niger. They were isolated from $37-60 \%, 23-$ $74 \%$ and $49-51 \%$ of the samples on the three isolation media, respectively. Some fungal species were recovered on two media and not recovered on the third such as: $A$. fumigatus, $A$. sclerotiorum, on glucose- and starch and not on $10 \% \mathrm{NaCl}$, whereas $A$. ochraceus on starch and $10 \% \mathrm{NaCl}, A$. terreus on glucose- and $10 \% \mathrm{NaCl}$. On the other hand, A. egyptiacus and $A$. versicolor were isolated from the tested samples on glucose- or on the three isolation media in rare occurrence, (Table 1). There are records which showed that some of these fungi produced several toxic substances (Debeaupuis and La Font, 1978; Charles et al., 1979; Wyllie and Morehouse 1977) and such foodstuffs could possibly be unsuitable for human consumption, if heavily contaminated. The results of the present work are in close agreement with those recorded by Megalla et al. (1985) and Aran and Eke (1987) who noticed that $A$. niger and $A$. flavis were the most common in the Egyptian and the Turkish foodstuffs, respectively. Also, Aspergillus species were isolated from snacks and biscuits substrates in high occurrence as reported by Zohri et al. (1995); Abdel Sater and Ismail (1993). All Aspergillus species isolated in the current study were encountered previously in various types of foodstuffs, seeds and grains in Egypt (El-Kady et al., 1982; AbdelHafez, 1982; Zohri, 1990) and in many parts of the world (Salcado and De Carvalho, 1980; Supriaman and Palmer, 1981 and Abdel-Hafez, 1984; Lund et al., 1996; Viljoen and Holy, 1997; Siame et al., 1998).

Penicillium (five species) was the second common genus behind Aspergillus representing $51 \%, 40 \%$ and $43 \%$ of the samples constituting $23.2 \%, 20 \%$ and $18.7 \%$ of the total fungi on the three media used, respectively. From the five species identified $P$. chrysogenum and $P$. corylophilum were the prevalent species. They were isolated from $11-43 \%$, 
$17-29 \%$ and $14-26 \%$ of the samples contributing $2.6-16.6 \%, 5.7-10.7 \%$ and $5.9-7.8 \%$ of total fungi, respectively (Table 1). Penicillium oxalicum and $P$. aurantiogriseum were only isolated, in low or rare occurrence from two media and not encountered from the third medium (Table 1). The obtained results were nearly similar to those obtained by Zohri et al. (1995) and Abdel-Sater and Ismail (1993). They reported that the genus Penicillium was the most prevalent behind Aspergillus in some foodstuffs, snacks and biscuits. Also, Penicillium species were previously reported as common fungi in several food materials or grains and seeds or some breads as indicated by Megalla et al., 1985; Aran and Eke, 1987; Pitt and Hocking, 1985; Lund et al., 1996; Viljoen and Holy, 1997; Siame et al., 1998.

Eurotium (2 species) as halophilic genus, which was isolated only from one sample on glucose-Czapek's agar and not on starch agar, and was in high occurrence on medium supplemented with $10 \% \mathrm{NaCl}$. It was represented in $54 \%$ of the samples comprising $24.7 \%$ of total fungi. $E$. amstelodami ( $43 \%$ of the samples) and E. chevalieri $(31 \%)$ were only identified using 10\% sodium chloride-Czapek's agar (Table 1). This genus was also previously isolated from different food, seeds and grains on media containing $20-50 \%$ sucrose or supplemented with different concentrations of sodium chloride (Abdel-Sater and Ismail 1993; Zohri et al. 1995; Lund et al., 1996; and several authors).

The remaining identified fungi were rare in frequency of occurrence on one or two medium. These were: Acremonium strictum (6\%), Cochliobolus spicifer and Neurospora crassa (3\% each) on starch-Czapek's agar; Altrenaria alternata and Gibberella fujikuroi $(6 \%$ and $3 \%)$ on glucose-; Emericella nidulans ( $9 \%$ ) on $10 \% \mathrm{NaCl}-;$ Cladosporium cladosporioides ( $9 \%$ and $6 \%$, respectively) on glucose- and $10 \% \mathrm{NaCl}$ whereas Rhizopus stolonifer ( $9 \%$ and $3 \%$ ) on glucose- and starch-Czapek's agar (Table 1). These fungi were isolated from other food and foodstuffs (Pitt and Hocking, 1985; Megalla et al., 1985; Aran and Eke, 1987; AbdelSater et al., 1993; Zohri et al., 1995; Hartog, 1981; King et al., 1981; Odell, 1983; Samson et al., 1995; Scholte, 1995; Ismail, 1993; King et al., 1979).

In the present study the most prevalent species were screened for their ability to produce amylase enzyme as shown in Table (2). The results indicated that among 60 isolates, representing 19 species appertaining to 9 genera, $36(60 \%)$ isolates could produce amylase and degraded the soluble starch into glucose (Table 2). Of the positive fungal isolates 10 isolates $(27.7 \%)$ showed high amylase activity and these related to A. flavus, $A$. niger, A. ustus, A. versicolor, C. cladosporioides and $P$. aurantiogriseum. 
Of the remainder, 26 isolates had moderate and weak activity (13 isolates each) and these are the fungi belonging to A. strictum, A. ochraceus, $A$. sydowii, C. spicifer, E. amstelodami, P. chrysogenum and P. oxalicum (Table 2). These results agree with those obtained by El-Kady et al . (1984), who concluded that about $88 \%$ of cultures tested were amylase producers. Also, Ismail (1993) showed that about $75 \%$ of 248 isolates had the ability to produce amylase. More recently Abdel-Sater and Ismail (1995) noticed that among 69 isolates tested for their ability to produce amylase enzyme, 61 isolates could produce this enzyme.

\section{REFERENCES}

Abdel-Hafez S.I.I. (1984): Composition of the fungal flora of four cereal grains in Saudi Arabia. Mycopathologia 85: 53-57.

Abdel-Sater M.A. and Ismail M.A. (1993): Ecological and enzymatic studies on fungi associated with biscuits in Egypt. International Biodeterioration and Biodegradation 31: 277-292.

Aran N. and Eke D. (1987): Mould mycoflora of some Turkish cereals and cereal products. Mircen J. 3: 281-287.

Beuchat R.L. (1978): Food and Beverage Mycology. Avi. Pub. Co. Inc., Wastport, Connecticut.

Bridge P.D. (1985): An evaluation of some physiological and biochemical methods as an aid to the characterization of species of Penicillium sub-section Fasciculata. J. Gen. Microbiol. 131: 1887-1895.

Charles P.; Grost-Allman and Steyn P.S. (1979): Structural elucidation of the nigerones, four new naphthopyrones from cultures of Aspergillus niger. J. Chem. Soc. Perkin 1: 2474-2479.

Debeaupuis J.P. and La Font P. (1978): Fumitoxins, new mycotoxins from Aspergillus fumigatus Fres. Appl. and Environ. Microbiol. 35: 810.

Domsch K.W.; Gams W. and Anderson T.H. (1980): Compendium of soil fungi. Academic Press London.

El-Kady I.A.; Abdel-Hafez S.I.I. and El-Maraghy S.S. (1982): Contribution to the fungal flora of cereal grains in Egypt. Mycopathologia 77: 103-109.

El-Kady I.A.; Mazen M.B. and Saber S.M. (1984): Some enzymatic activities of fungi isolated from cotton seeds and cotton seed products. Qatar Univ. Sci. Bull. 4: 85-93. 
FAO (1979): Food and Nutrition, paper No. 13 presespective on mycotoxins. Food and Agricultural Organization of the United Nations, Rome.

Hartog B.I. (1981): The detection and quantification of fungi in Food. In Introduction to food-borne fungi. (ed. R.A. Samson, E.S. Hoekstra and C.A.N. Van Oorschot) Centraalbureau Voor Schimmelcultures, Baarn, The Netherlands, pp. 206-211.

Hartog B.J. and Kuik D. (1984): Mycological studies on Dutch rye bread.

In Microbial Associations and Interactions in Food. (ed. Kiss; Deak T. and Incze K.) pp. 241-246. Dordrecht: D. Reidel Publishing Company.

Ismail M.A. (1993): Degratitive enzymes and fungal flora associated with the Egyptian foodstuffs kishk. Inter. Biodet. Biodeg. 31: 143-157.

King A.D.; Hocking A.D. and Pitt J.I. (1979): Dichloran-rose-bengal medium for the enumeration and isolation of molds from foods. Appl. Environ. Microbiol. 37: 959-964.

King A.D.; Hocking A.D. and Pitt J.I. (1981): The mycoflora of some Australian foods. Food Technol. Aust. 33: 55-60.

Kozakiewicz Z. (1989): Aspergillus species on stored products (Mycological papers No. 161) International Mycological Institute, Kew, Surrey, UK.

Lacey J. (1988): The microbiology of cereal grains from areas of Iran with a high incidence of oesophageal cancer. J. Stored Prod. Res. 24 (1): 39-50.

Leistner L. (1984): Toxigenic Penicillia occurring in feeds and foods: a review. Food Technol. Aust. 36: 404-406.

Lund F.; Filtenborg O.; Westall S. and Frisvad J.C. (1996): Associated mycoflora of rye bread. Letter in Applied Microbiology 23: 213 217.

Megalla S.E., Abdou R.F. and Bagy M.M.K. (1985): Fungal flora of Egyptian baladi bread with special reference to the mutagenic effects of their toxic metabolites. Mycopathologia 89: 35-41.

Odell D.E. (1983): Fungi isolated from incubated commercial wheat germ produced in the UK during 1982-83. FMBRA Bull. 6: 281-286.

Pitt J.I. (1979): The genus Penicillium and its teleomorphic states, eupenicillium and Talaromyces. Academic Press, London.

Pitt J.I. and Hocking A.D. (1985): Fungi and Food spoilage Academic Press, Sydney, New South Wales, Australia. 
Raper K.B. and Fennell D.I. (1977): The genus Aspergillus. R.E. Krieger Publishing Company, Washington, D.C.

Salcado T.M. and De Carvalho J.B. (1980): Toxigenic fungi associated with grains. I- Survey of microflora associated with corn, wheat and rice. Rev. Microbiol. 11: 60-63.

Samson R.A.; Hoekstra E.S.; Frisvad J.C. and Filtenborg O. (1995): Introduction to food-borne fungi. 4th edn. Bearn: Centraalburea voor Schimmelculturs.

Scholte R.P.M. (1995): Spoilage fungi in the industrial processing of food. In Introduction to Food-borne fungi, 4th edn, Samson R.A.; Hoekstra, E.S.; Frisvad J.C. and Filtenborg O. pp. 275-288. Baarn: Centraalbureau voor Schimmel culures.

Seiler D.A.L. (1986): Preventing mould growth on bakery products using ovenable. Lined fibreboard containers. FMBRA Bull. 6: 281-285. Seiler D.A.L. (1987): The mould-free shelf life of bread. FMBRA Bull. 5: 133-136.

Siame B.A.; Mpuchane S.F.; Gashe B.A.; Allotey J. and Teffera G. (1998): Occurrence of aflatoxins, Fumonisin B1, and zearalenone in foods and feeds in Botswana. J. Food Protect. 61 (12): 1670-1673.

Supriaman J. and Palmer L.T. (1981): Seed-borne fungi of rice in Indonesia. Contributions of Central Research Institute for Agriculture, Bogor D (570: 1-12.

Viljoen C.R. and Holy A. (1997): Microbial populations associated with commercial bread production. J. Basic Microbiol. 37 (6): 439-444. Wyllie T.D. and Morehouse L.G. (1977): Mycotoxic fungi, Mycotoxins, Mycotoxicoses. Vol. I. Mycotoxic fungi and chemistry of Mycotoxins. Marcel Dekker, Inc., New York.

Zohri A.A. (1990): Mycoflora and mycotoxins of some meat products. Ph.D. Thesis, Botany Department, Faculty of Science, Assiut University, Assiut, Egypt.

Zohri A.A.; Abdel-Sater M.A. and Ismail M.A. (1995): Incidence of aflatoxins and mould flora in corn snacks. J. Food Science and Technology 32: 289-294. 
Assiut Vet. Med. J. Vol. 42 No. 83, October 1999

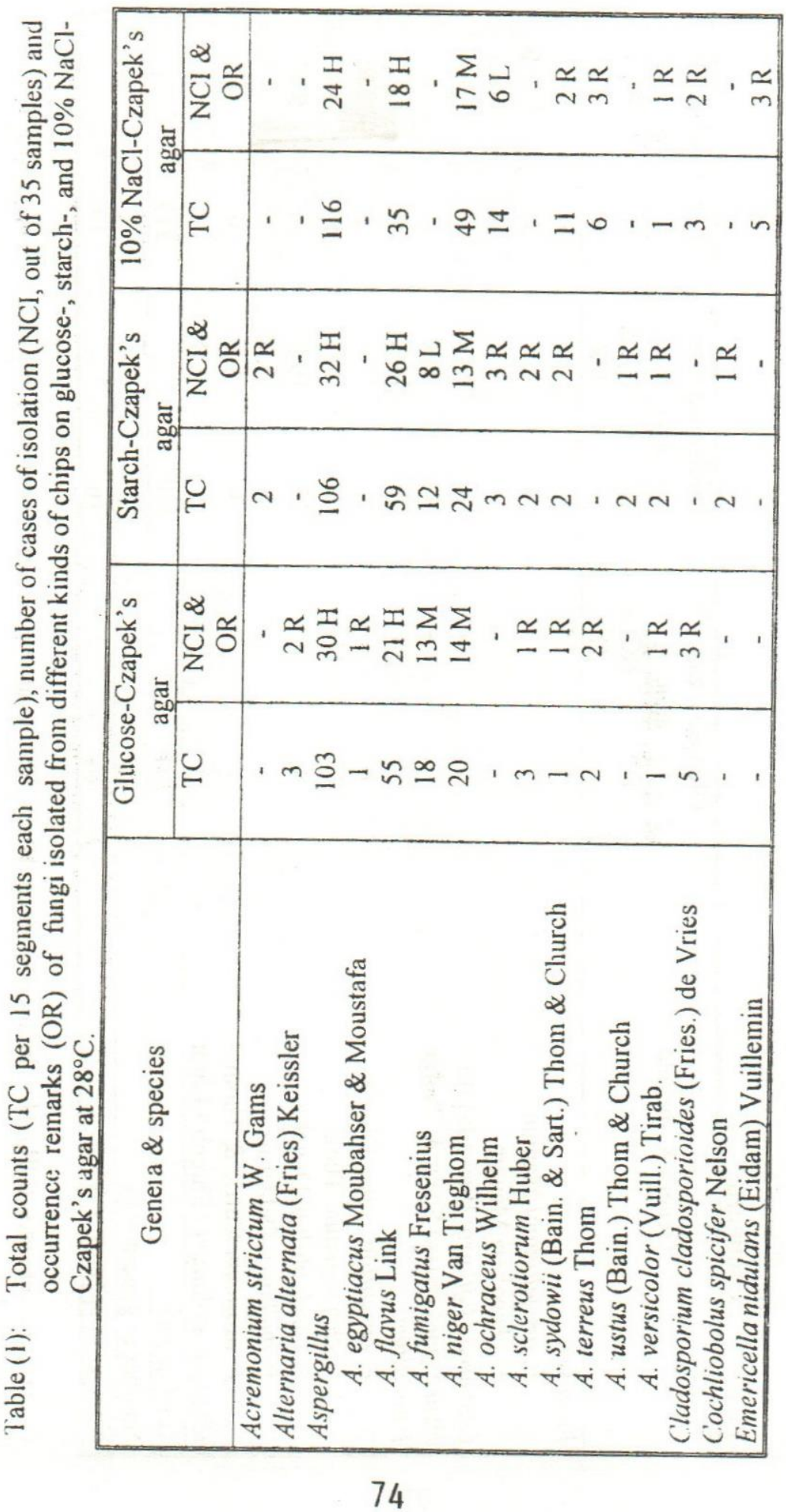


Assiut Vet. Med. J. Vol. 42 No. 83, October 1999

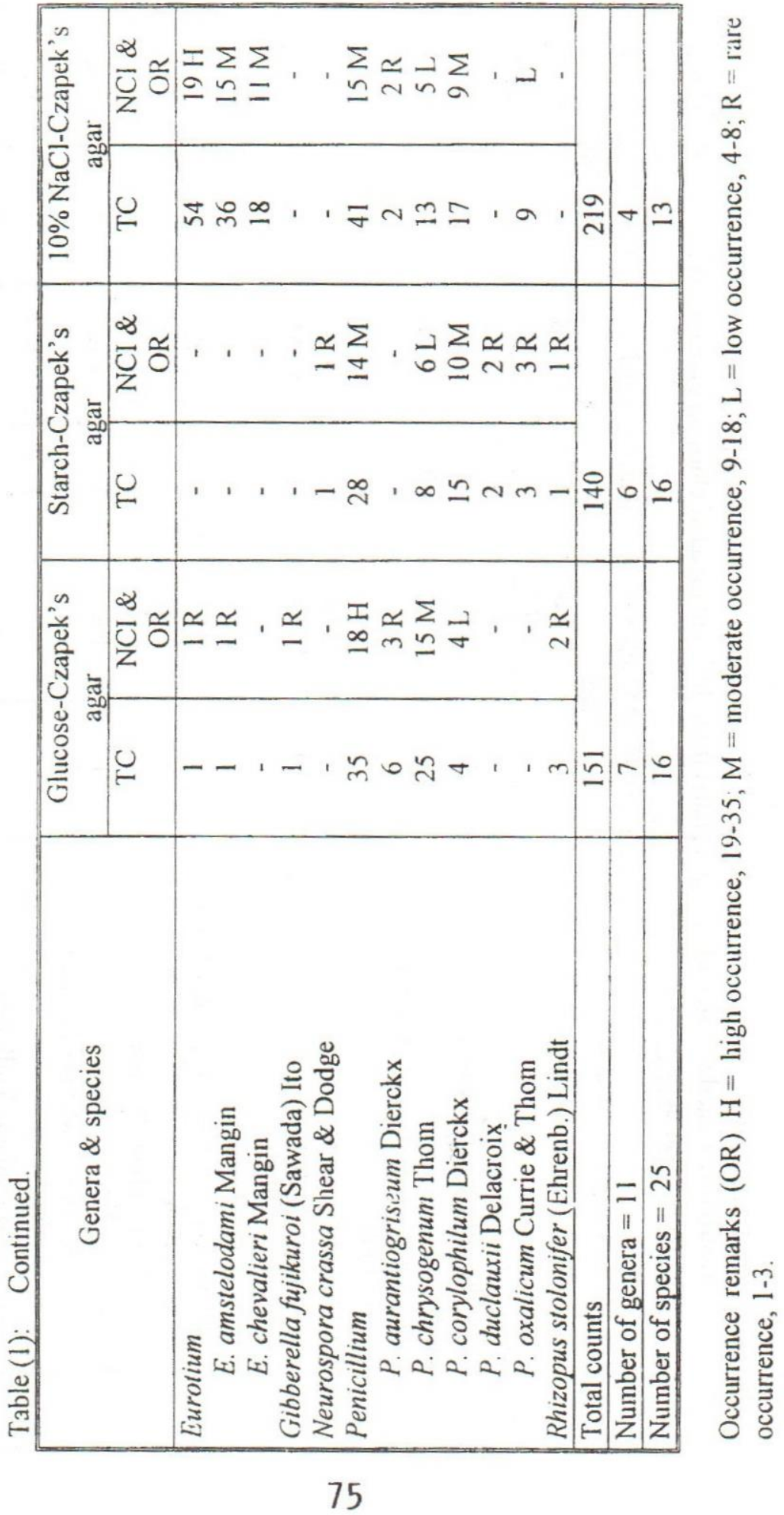


Table (2): Ability of common fungal species isolated from chipsy to produce amylase enzyme .

\begin{tabular}{|c|c|c|c|c|c|}
\hline \multirow[t]{2}{*}{ Organisms } & \multirow[t]{2}{*}{ NIT } & \multicolumn{4}{|c|}{ Degree of production } \\
\hline & & ++ & t+ & + & -ve \\
\hline Acremonum strectum & 2 & - & - & 2 & - \\
\hline Alternaria alternata & 1 & - & - & - & 1 \\
\hline Aspergillus flavus & 6 & 1 & 1 & - & 4 \\
\hline A. fumigatus & 3 & - & - & - & 3 \\
\hline A. niger & 5 & 3 & 2 & - & - \\
\hline A.ochraceus & 3 & - & 3 & - & - \\
\hline A.sydowii & 3 & - & 1 & 2 & - \\
\hline A. terreus & 4 & - & - & 3 & - \\
\hline A.ustus & 4 & 1 & - & 3 & - \\
\hline A.versicolor & 3 & 1 & 1 & - & 1 \\
\hline Cladosporium cladosporioides & 2 & 1 & - & - & 1 \\
\hline Cochliobolus spicifer & 2 & - & 2 & - & - \\
\hline Emericella nidulans & 6 & - & - & 1 & 5 \\
\hline Eurotium amstelodami & 2 & - & 1 & 1 & - \\
\hline Gibberella fujikuroi & 3 & 3 & - & - & - \\
\hline Psenicillum aurantiogriseum & 3 & 3 & - & - & - \\
\hline P. chrysogenum & 4 & - & 1 & 1 & 2 \\
\hline p. corylophilum & 3 & - & - & - & 3 \\
\hline P. oxalicum & 2 & - & 1 & - & 1 \\
\hline Total isolates & 60 & 10 & 13 & 13 & 24 \\
\hline
\end{tabular}

NIT $=$ number of isolates tested .

$++=$ high enzyme producers $;++=$ moderate producers $;+=$ weak producers ; $-\mathrm{ve}=$ negative isolates . 
